\section{Metástasis en falange distal como primera manifestación de un carcinoma indiferenciado de pulmón}

\section{Sr. Director:}

Un $40 \%$ de los pacientes con carcinoma de pulmón de célula no pequeña presentan metástasis a distancia (estadio IV) en el momento del diagnóstico inicial.

En este estadio las posibilidades quirúrgicas se limitan a algunos pacientes con metástasis solitarias sincrónicas o metacrónicas en el cerebro, pulmón ipsilateral y en las glándulas adrenales $(1,2)$.

Las metástasis pueden producirse por vía linfática o a través de los vasos sanguíneos y en ocasiones son tan precoces que la sospecha clínica se realiza después del diagnóstico dela localización metastásica.

Las metástasis hepáticas y en las glándulas adrenales son las localizaciones más frecuentes en las series necrópsicas, pero en la práctica clínica únicamente están presentes en el momento del diagnóstico en el $1 \%$ de los casos de pacientes con carcinoma de pulmón no microcítico.

Las metástasis óseas aparecen hasta en un 25\% de los pacientes y suelen ser osteolíticas. Las localizaciones más frecuentes son: columna vertebral, pelvis y fémures. Es muy rara la localización en falanges distales, pero cuando ocurre es un dato de mal pronóstico.

El método diagnóstico más eficaz para detectar la afectación ósea es mediante la realización de una gammagrafía ósea $(3,4)$.

La afectación metastásica constituye un factor pronóstico fundamental en los pacientes con carcinoma de pulmón (5).

Por su rareza presentamos el caso de un paciente que presentó una metástasis en falange distal como primera manifestación de un carcinoma indiferenciado no de célula pequeña de pulmón.

Varón de 54 años de edad, con antecedentes personales de fumador de 60 cigarrillos al día, bebedor de más de 100 gramos de alcohol al día, hipertensión arterial en tratamiento con diltiazem y síndrome depresivo en tratamiento con fluoxetina.

Consultó a otro médico tras presentar un cuadro doloroso en el $5^{\circ}$ dedo de la mano derecha de tres semanas de evolución. A la exploración física existían marcados signos inflamatorios y ante la sospecha de proceso infeccioso se realizó un tratamiento antibiótico prolongado con cefuroxima sin obtener respuesta. El estudio radiológico fue informado de osteolísis completa de la falange distal con aumento de partes blandas.

Posteriormente fue intervenido por el servicio de traumatología realizándose una amputación de la falange distal del $5^{\circ}$ dedo.

El estudio anatomopatológico informó de la existencia de una infiltración por un carcinoma pobremente diferenciado que destruía el tejido óseo e infiltraba las partes blandas adyacentes.

Fue remitido desde traumatología al servicio de cirugía general, donde se solicitó una tomografía axial computarizada abdominal. En dicha prueba se detectaron 6 lesiones focales hepáticas de aspecto sólido, sugestivas de metástasis. Además se detectaron metástasis esplénicas y una lesión nodular de 5 centímetros en el músculo oblicuo externo derecho que sugería metástasis. Asimismo existían múltiples adenopatías mesentéricas y retroperitoneales de tamaño patológico.

Se realizó una PAAF de la lesión muscular, siendo informada como: células malignas correspondientes a un tumor indiferenciado con celularidad fusiforme y epiteloide.

Finalmente fue derivado a la consulta de oncología. El paciente se encontraba con una deterioro físico severo. A la exploración física se apreciaba una hepatomegalia a 4 centímetros del reborde costal. No se palpaban adenopatías periféricas.

Laboratorio: Hemograma y bioquímica normales, excepto GGT de 141 U/L y LDH de 1438 U/L. CEA, Ca 19.9, PSA y alfa fetoproteína normales.
Radiografía de tórax: atelectasia del lóbulo superior derecho y múltiples nódulos bilaterales. Una TAC torácica no aportó más información.

Gammagrafía ósea: afectación ósea múltiple de tipo osteolítico.

Se realizó una broncoscopia observándose una oclusión del bronquio del lóbulo superior derecho por una lesión de aspecto neoformativo. La biopsia fue informada de carcinoma pobremente diferenciado no de célula pequeña.

En resumen el paciente presentaba un carcinoma indiferenciado de pulmón no de célula pequeña, con metástasis óseas, musculares, hepáticas, esplénicas y ganglionares.

En este momento teniendo en cuenta el pésimo estado del paciente, se decidió realizar únicamente tratamiento sintomáticopaliativo, produciéndose el fallecimiento pocas semanas más tarde.

\section{F. Marcos Sánchez, M. I. Albo Castaño, A. Viana Alonso, J. Gómez Martín, F. Juárez Ucelay}

Servicio de Medicina Interna-Oncología Médica. Hospital Nuestra Señora del Prado. Talavera de la Reina. Toledo

1. Font Pous A, Rosell Costa R. Cáncer de pulmón. Neoplasias del mediastino. Mesotelioma. En Oncología Clínica básica de Díaz-Rubio E, García-Conde J. Madrid: Arán Ediciones 2000. p. 387-400.

2. Rosell R, Maestre J, Molina F. Cáncer de pulmón de célula no pequeña. Oncología médica de Rosell R, Abad A, Monzó M, Molina F. Madrid: Ediciones Ergón, 1995. p. 153-166.

3. Silvestri GA, Littenberg B, Colice GL. The clinical evaluation for detecting metastatic lung cancer. A meta-analysis. Am J Respir Crit Care Med 1995; 152: 225-230.

4. Márquez Pérez FL, Blasco FR, Callol SL, Chivato PT, Villegas FF, Gómez de Terreros Sánchez FJ. Valor de los datos clínicos en la predicción de metástasis óseas estudiadas por rastreo isotópico en el carcinoma broncogénico. Arch Bronconeumol 1998; 34: 484-488.

5. Feld R, Arriagada R, Ball DL, Mattson K, Sorensen JB. Prognostic factors in non-small cell lung cancer: a consensus report. Part I. Lung Cancer 1991; 7:3-5.

\section{Anemia hemolítica en una paciente en tratamiento} con capecitabina. Descripción de un caso y revisión de la literatura

\section{Sr. Director:}

La anemia hemolítica se ha descrito como complicación asociada a un amplio número de agentes quimioterápicos, entre ellos las fluoropirimidinas. Este efecto secundario generalmente no da síntomas y es en la mayoría de ocasiones reversible. La capecitabina es un profármaco del 5-FU en forma de fluoropirimidina carbamato, teniendo un mecanismo de acción similar, con la diferencia de que disminuye la concentración en tejidos sanos y la toxicidad sistémica asociada (1). Su mecanismo de acción se basa en la inhibición de la síntesis de folato. Dado que el folato es necesario para la síntesis y reparación del DNA, los tejidos con una rápida división, como el tracto gastrointestinal y las células hematopoyéticas son los principales focos de toxicidad, teniendo como efectos secundarios principales la mucositis, diarreas y la mielosupresión (siendo ésta menos frecuente que con el 5-FU en bolus) (2). El síndrome mano-pie también se ve en un 15-20\% de 
los pacientes. Asocia además toxicidad neurológica caracterizada por somnolencia, confusión, temblores, ataxia cerebelosa y, rara vez, encefalopatía. Pueden aparecer por otra parte mialgias, fiebre, hipocalcemia, así como cierto potencial trombótico (3).

En nuestro caso, observamos la aparición de hiperbilirrubinemia en la bioquímica de una paciente que estaba recibiendo capecitabina en el contexto de un ensayo clínico aleatorizado en la adyuvancia de un tumor de mama con axila afectada. Se trataba de una mujer premenopáusica de 40 años. Entre sus antecedentes médicos figuraba un síndrome de Gilbert descrito 12 años atrás y un hábito tabáquico de 10 años/paquete. Realizaba vida activa y plena y la exploración física era anodina. Se realizó una tumorectomía y linfadenectomía, por un tumor de $2,2 \mathrm{~cm}$, con 1 ganglio afectado de 11 aislados, por lo que se le ofreció completar tratamiento con quimioterapia + radioterapia secuenciales adyuvantes. Recibió inicialmente cuatro ciclos de antraciclinas (Epirrubicina $90 \mathrm{mg} / \mathrm{m}^{2}$ + ciclofosfamida $600 \mathrm{mg} / \mathrm{m}^{2}$ ) que se debían de seguir de cuatro ciclos de Capecitabina (Xeloda $\left.{ }^{\circledR}\right) 1.250$ $\mathrm{mg} / \mathrm{m}^{2}$ en monoterapia. En las analíticas previas a cada ciclo de quimioterapia había presentado tendencia a la anemia (Hb 10 $\mathrm{mg} / \mathrm{dl}$ ), además de cifras de bilirrubinemia discretamente elevadas $(2,1 \mathrm{mg} / \mathrm{dl})$, que se habían atribuido a su síndrome de Gilbert. No obstante, tras su segundo ciclo de capecitabina se observó que presentaba bilirrubina total de $7 \mathrm{mg} / \mathrm{dl}$, con una bilirrubina indirecta de $5 \mathrm{mg} / \mathrm{dl}$, una cifra de hemoglobina de $8 \mathrm{mg} / \mathrm{dl}$, haptoglobina de $390 \mathrm{mg} / \mathrm{dl}$, LDH de $750 \mathrm{mg} / \mathrm{dl}$ y un recuento de reticulocitos aumentado. Clínicamente se encontraba asintomática, excepto por una discreta astenia grado I. En este momento, se suspende transitoriamente el tratamiento quimioterápico y se remite a la paciente a hematología. Tras retirar esporádicamente el agente causal, presentó una rápida normalización de los valores analíticos reseñados, no obstante se decidió suspender definitivamente el tratamiento quimioterápico, puesto que se trataba de un tratamiento adyuvante y la paciente ya había recibido cuatro ciclos de antraciclinas y dos de capecitabina.

La anemia hemolítica es una condición que se caracteriza por la presencia de un número inadecuado de glóbulos rojos ocasionada por su destrucción prematura. Se presenta cuando la médula ósea es incapaz de compensar dicha destrucción por medio del aumento en su producción. Existen varios tipos de anemia hemolítica que se clasifican según la ubicación del defecto, el cual puede estar dentro del glóbulo rojo sanguíneo (factor intrínseco) o fuera de éste (factor extrínseco). Algunas de las causas de la anemia hemolítica son: infecciones, ciertos medicamentos, trastornos autoinmunes y trastornos hereditarios. La anemia hemolítica inducida por fármacos ocurre con poca frecuencia, aunque hasta la fecha se ha visto asociación con aproximadamente 100 fármacos, fundamentalmente la metildopa y antibióticos beta-lactámi$\cos (4)$.

Entre los síntomas que pueden aparecer se encuentran el síndrome anémico (astenia, palidez, taquicardia), así como ictericia, coluria y esplenomegalia. En cuanto a los parámetros analíticos, podemos encontrar, hiperbilirrubinemia (a expensas de bilirrubina indirecta), haptoglobina sérica baja, hemoglobinuria, hemosiderinuria, aumento del urobilinógeno urinario y fecal, elevación del número absoluto de reticulocitos, descenso de hemoglobina y LDH sérico elevado.

El tratamiento depende del tipo y de la causa de la anemia hemolítica. Se puede usar ácido fólico, suplementos de hierro y corticosteroides; así como intentar eliminar el agente causal si es posible.

\section{S. Maciá Escalante, A. Rodríguez Lescure, N. Martínez Banaclocha, J. Gallego Plazas, A. Carrato Mena}

Servicio de Oncología. Hospital General Universitario de Elche, Alicante
1. Dooley M, Goa KL. Capecitabine. Drugs 1999; 58: 64-7.

2. Nikolic-Tomasevic Z, Jelic S, Cassidy J, Filipovic-Ljeskovic I, Tomasevic $Z$. Fluoropyrimidine therapy: hyperbilirubinemia as a consequence of hemolysis. Cancer Chemother Pharmacol. 2005: 594-602. Epub 2005 Jul 26.

3. Maciá Escalante S, Guillén Ponce C, Molina Garrido MJ, Carrato Mena A. Patient with angina secondary to capecitabine. Clin Transl Oncol 2005; 7: 335

4. Arndt PA, Garratty G. The changing spectrum of drug-induced immune hemolytic anemia. Semin Hematol 2005; 42: 137-44.

\section{Neumonía adquirida en la comunidad y bacteriemia por Alcaligenes xylososidans}

\section{Sr. Director:}

Alcaligenes xylosoxidans es un bacilo aerobio gram negativo que habita en ambientes acuáticos, tanto extra como intrahospitalarios (1). A pesar de ser considerado colonizador del tubo digestivo, raramente causa enfermedad en humanos, soliendo afectar a pacientes hospitalizados, inmunodeprimidos, con neoplasias sólidas o hematológicas $(2,3)$. La aparición de neumonía por este microorganismo es excepcional. Presentamos el caso de una paciente inmunodeprimida afecta de neumonía bacteriémica por A. xylosoxidans, con desenlace fatal.

Mujer de 71 años con antecedentes de artritis reumatoide de 30 años de evolución, portadora de marcapasos definitivo, así como hipertensión arterial y cardiopatía isquémica. Su tratamiento habitual incluía diariamente: prednisona $5 \mathrm{mg}$, AAS $100 \mathrm{mg}$, valsartán $80 \mathrm{mg}$, calcio $500 \mathrm{mg}$, paracetamol $1000 \mathrm{mg}$, fentanilo transdérmico $25 \mathrm{mg} / 72 \mathrm{~h}$ y rofecoxib $25 \mathrm{mg}$. Como complicaciones del tratamiento había presentado fracturas osteoporóticas en $4^{\mathrm{a}}$ y $11^{\mathrm{a}}$ vértebras dorsales, y costales múltiples tras traumatismo torácico banal 6 meses antes. Acudió a Urgencias por cuadro de cuatro días de evolución consistente en disnea progresiva hasta ser de reposo, junto con tos y expectoración abundante amarillenta. Negaba dolor torácico, fiebre u otra sintomatología. El proceso no había mejorado tras recibir tratamiento con levofloxacino $500 \mathrm{mg}$ al día. A la exploración se encontraba consciente y orientada, con regular estado general, taquipnea de $30 / \mathrm{min}$ sin cianosis respirando aire ambiente, tensión arterial 130/80 $\mathrm{mmHg}$ y $\mathrm{T}^{\mathrm{a}}$ $35^{\circ} \mathrm{C}$. Destacaba delgadez, deformidades articulares en extremidades y cifosis dorsal. La auscultación mostró ruidos cardiacos rítmicos sin soplos a 110 latidos por minuto y en la pulmonar disminución global del murmullo vesicular con crepitantes bilaterales y roncus difusos. En extremidades existían ligeros edemas con fóvea bimaleolares, sin signos de trombosis venosa profunda, siendo el resto normal. En la analítica existía 15.300 leucocitos $/ \mathrm{mm}^{3}$ con fórmula normal, hemoglobina $9.7 \mathrm{~g} / \mathrm{dl}$, hematocrito $30.2 \%$, VCM $99.3 \mathrm{fl}$ y 194.000 plaquetas. Tanto la bioquímica como la coagulación no mostraron alteraciones de interés. La gasometría arterial $\left(\mathrm{FiO}_{2}\right.$ 0,5) mostró pH 7.40, $\mathrm{PCO}_{2} 50 \mathrm{mmHg}$, $\mathrm{PO}_{2} 78.4 \mathrm{mmHg}, \mathrm{HCO}_{3} 30 \mathrm{MM} / 1, \mathrm{SaO}_{2} 95,2 \%$, con un gradiente alveolo arterial de $\mathrm{O}_{2}$ de $213 \mathrm{mmHg}$. El ECG reveló ritmo sinusal a $120 \mathrm{lpm}$ alternando con ritmo de marcapasos. En la radiografía de tórax (Fig. 1) se observaba aumento difuso de densidad en hemitórax derecho con mínimo derrame pleural e infiltrado alveolar en lóbulo inferior, elongación y calcificación aórtica, aumen- 